\title{
Rapid drug trial offers hope to CJD patients
}

\section{Jim Giles, London}

Britain's Medical Research Council is set to embark on a rigorous clinical trial of a treatment for Creutzfeldt-Jakob disease (CJD). The trial will initially assess the effects of only one drug - a compound that few experts expect to be effective. But the trial has been designed to allow newly discovered drugs to be rapidly tested, a move that doctors hope will sort out the chaos that has been caused in the past by dying patients' demands for access to untested treatments.

The study, which is expected to receive final ethical approval within the next few months, will look at treatments for all forms of CJD. This includes variant CJD thought to be contracted through eating meat infected with bovine spongiform encephalopathy (BSE) - and sporadic CJD, a rare condition with no known cause. About 900 people in Britain have died from these diseases since 1990.

Patients have been eager to get their hands on any possible treatment for these conditions. That includes quinacrine - the drug that will be tested first in the trial. Quinacrine, which was initially developed as a malaria treatment, was shown in lab tests with cell cultures to inhibit the formation of prions - the proteins thought to cause CJD (C. Korth, B. C. H. May, F. E. Cohen and

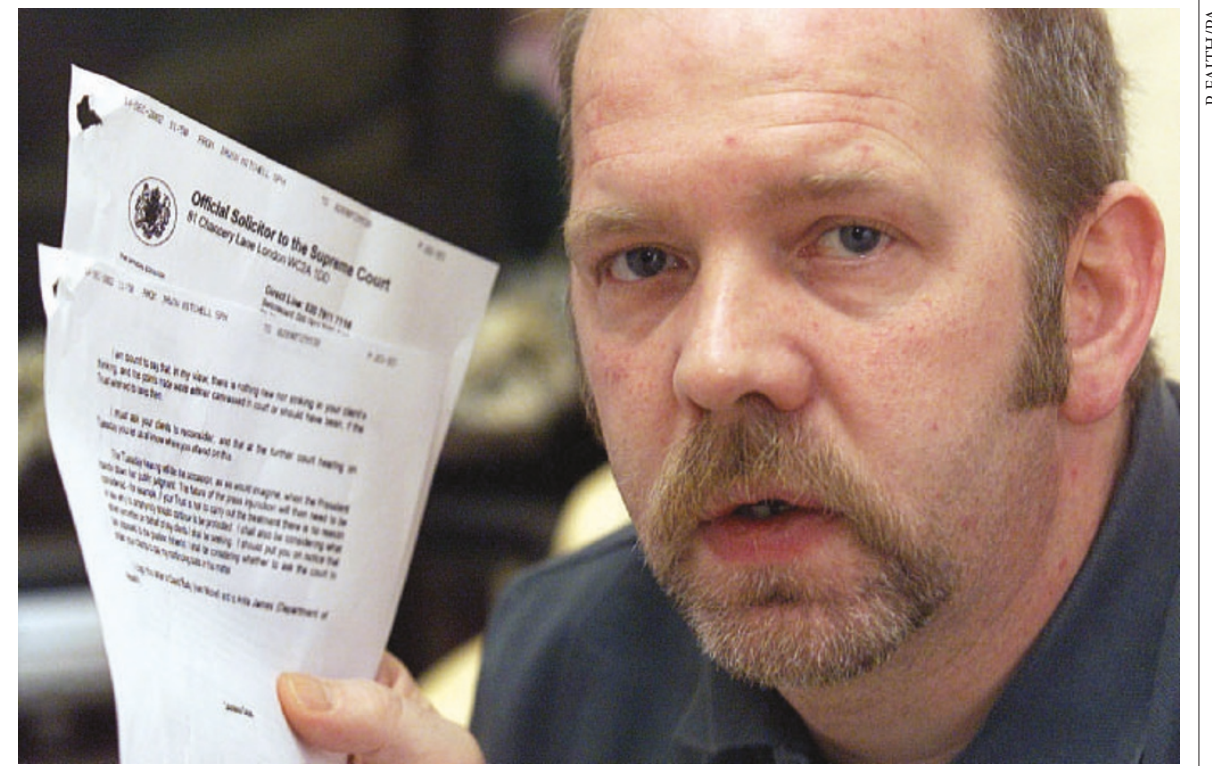

Court battle: Don Simms of Belfast, UK, with the papers allowing his son Jonathan to start pentosan treatment last January. Jonathan has improved slightly, but the drug is not included in the new trial.

S. B. Prusiner Proc. Natl Acad. Sci. USA 98, 9836-9841; 2001). Stanley Prusiner, who led that study and also won a 1997 Nobel Prize for his work on prions, backed the use of quinacrine to treat CJD patients and, at around the same time, reported that the symptoms of a British CJD sufferer had improved after taking the drug.

\section{Europe eyes merit-based agency}

\section{Alison Abbott, Brussels}

The European Union (EU) last week edged closer to setting up a new research agency that would be run by scientists and would give out grants purely on the basis of scientific merit.

Achilleas Mitsos, director-general of the European Commission's research directorate, said last week that the commission would publish a position paper within the next few weeks for a "major programme in basic research where excellence is the sole and exclusive priority, and where evaluation will be in the hands of the scientific community".

Until now, the EU has funded only small amounts of basic research under its Framework research programmes, which are designed primarily to support applied research. Most basic research is supported by national research councils.

Mitsos was speaking at a meeting last month in Brussels of research directors from Germany's Max Planck Society, members of the research commission and research commissioner Philippe Busquin.
The concept that Mitsos proposed is close to the advice given by an expert group, which recently called for a European Research Council to be set up, financed with EU money but run independently of European Commission officials (see Nature 425, 440; 2003).

Mitsos said that the commission will not use the term 'European Research Council' in its document, pointing out that although the concept has been intensively discussed in the scientific community during the past couple of years, it has not been discussed in political circles.

The commission's paper will, however, be discussed in spring by the European Council of Ministers and by members of the European Parliament.

"We have to do this in a clever way," Mitsos said. "The commission cannot afford to propose something that would be rejected - we have to prepare the ground." He hopes that the paper will persuade the council to ask the commission to prepare a formal proposal for a basic research council in the second half of next year.
Media coverage, as well as Prusiner's endorsement, led to a scramble to use the drug before any proper trial had been done, regardless of the fact that useful effects in cell cultures are often not replicated in animal tests. "It was premature to state that it was good for patients," says Adriano Aguzzi, a neuropathologist at University Hospital Zurich in Switzerland.

Since then, hopes for quinacrine have dimmed. Evidence from human CJD sufferers suggests that it has little effect, says Richard Knight, a neurologist at the National CJD Surveillance Unit in Edinburgh. Animal experiments carried out since then have also failed to show unambiguously that the drug works (P. Brown Neurology 58, 1720-1725; 2002).

Nevertheless, Knight says that the British trial will be welcomed by patients, as it should reveal whether quinacrine has any effect, however minor. More importantly, he adds, the trial will allow rigorous assessment of other drugs as soon as any potential benefit is revealed.

The trial will not put an end to the use of untested drugs, however. At present, one drug in demand from CJD patients is pentosan polysulphate. Unpublished work carried out by Katsumi Doh-ura, a prion researcher at Tohoku University in Sendai, Japan, suggests that this compound can delay the onset of symptoms in mice infected with disease prions.

Patients have taken the battle to court and won the right to be given the drug. But because it has to be injected into the brain, and is linked to side-effects such as impaired blood clotting, it has been considered too dangerous to include in the British trial. 